\title{
Pennation angle of vastus laterallis during isometric contractions performed at two knee angles
}

\author{
Ângulo de penação do vasto lateral durante contrações \\ isométricas executadas em dois ângulos do joelho
}

Felipe Torres Miranda de Oliveira ${ }^{[a]}$, Carlos Gomes de Oliveira ${ }^{[a]}$, Paulo Farinatti ${ }^{[b, c]^{*}}$

[a] Universidade Federal do Rio de Janeiro (UFRJ), Rio de Janeiro, RJ, Brazil

[b] Universidade do Estado do Rio de Janeiro (UERJ), Rio de Janeiro, RJ, Brazil

[c] Universidade Salgado de Oliveira (UNIVERSO), Rio de Janeiro, RJ, Brazil

\section{Abstract}

Introduction: The pennation angle (PA) of a muscle is not static value, but it adapts to the conditions imposed by the contraction intensity required. Objective: This study investigates the effect of knee angle (KA) and intensity of contraction (IC) on PA of vastus lateralis (VL). Methods: Eight women and nine men executed isometric torques lasting $5 \mathrm{~s}$ at the maximal voluntary contraction (MVC), 25\%, 50\% and $75 \%$ of $\mathrm{MVC}$, on an isokinetic dynamometer with the KA at $90^{\circ}$ and $120^{\circ}$ (full extension $=180^{\circ}$ ). The PA was measured in each test, and with the subject relaxed. The effect of IC on PA was tested by means of repeated measures ANOVA and effect size (ES), and of the KA on PA by paired t test, employed on each IC, together with the statistics: intraclass correlation (ICC), standard error of measurement (SEM) and ES, all calculated with the PAs measured at both KAs. Results: The PA increased significantly and successively with the IC ( $\mathrm{p}<0.05$; ES between 1.11 and 3.04), but was not influenced by KA ( $\mathrm{p}>$ 0.05 ; ICC between 0.70 and 0.81 ; SEM between $0.7^{\circ}$ and $1.4^{\circ}$; ES between 0.02 and 0.2 ). Conclusion: The successive increase of PA with the IC supports the existence of relation between these variables.

\footnotetext{
FTMO: MC, email: oliveiraftmufrj@gmail.com CGO: PhD, email: oliveiracg@yahoo.com PF: PhD, email: pfarinatti@gmail.com
} 
While studies advocate the effect of PA on joint angle this was not observed in this study, probable because the 30 o of between KA difference employed was not enough to provide change in PA.

Keywords: Angle. Knee Joint. Torque. Vastus Lateralis.

\section{Resumo}

Introdução: $O$ ângulo de penação (AP) de um músculo não é estático, podendo se adaptar às condições impostas pela contração demandada. Objetivo: Este estudo investigou a influência do ângulo do joelho (AJ) e da intensidade da contração (IC) no AP do vasto lateral (VL). Métodos: Oito mulheres e nove homens executaram torques isométricos durante 5 s na contração voluntária máxima (CVM), em 25\%, 50\% e 75\% da CVM, em um equipamento isocinético, com o AJ em $90^{\circ}$ e $120^{\circ}$ (extensão $=180^{\circ}$ ). $O$ AP foi medido nos testes e com o sujeito relaxado. $O$ efeito da IC no AP foi testado por ANOVA para medidas repetidas e pelo tamanho do efeito (TE), e o do AJ no AP, por teste t pareado, aplicado a cada IC, junto com as estatísticas: coeficiente de correlação intraclasse (ICC), erro padrão da medida (SEM) e TE, todas calculadas com os APs medidos em ambos AJs. Resultados: $O$ AP aumentou significativamente e sucessivamente com a IC ( $p<0,05$; TE entre 1,11 e 3,04), mas não foi influenciado pelo AJ ( $p>0,05$; ICC entre 0,70 e 0,81; SEM entre 0,7 e 1,4 ; TE entre 0,02 e 0,20). Conclusão: $O$ aumento sucessivo do AP com a IC corrobora a existência de relação entre estas duas variáveis. Enquanto estudos advogam efeito do ângulo articular no AP, isto não foi observado neste estudo, provavelmente porque a diferença de $30^{\circ}$ utilizada entre os AJ não foi suficiente para produzir mudança no AP.

Palavras-chave: Ângulo. Articulação do Joelho. Torque. Vasto Lateral.

\section{Introduction}

The muscular architecture takes part of the muscle mechanical properties related to its capacity of force producing, so that some researchers have the employed their components as input parameters of muscle strength modeling $(1,2)$. One of the studied components of the muscular architecture is the pennation angle (PA), which is considered an important functional attribute related to the mechanics of the musculotendinous unit $(3,4)$. Among the techniques employed to measure variables of in vivo muscle architecture, and particularly the PA, the ultrasound has been used at most, because it is a relatively low cost method, easy to handle, with good reproducibility of measurement, and further offer a minimum risk to the health of the subject to be tested $(1,5)$.

The PA changes due to some reasons (6), and may acutely or chronically increased because of strength training, while such increasing may be influenced by the intensity of stimulation produced by the exercise (6 - 8). In addition, it has been observed that the PA can undergo instantaneous influence of force or torque exerted by the muscle, as well it may be dependent on the angle of a given joint ( 9 - 11). The joint angle, in turn, influences the maximal capacity of muscle force generation, since this ability depends on the muscle length, and there is a relationship between this variable and joint angle (12 - 15). In this context, the torque generated during a maximal voluntary contraction (MVC) has reflected different relationships with the joint angle. More intense torque was found at angles where the muscle was elongated compared to the position in which it was shortened $(16,17)$. Conversely, Saito and Akima (18) found lower isometric strength of knee extensors at $90^{\circ}$ than at $120^{\circ}$ of flexion, an angle where the muscles are expected to be more shortened. To understand this apparent paradox, one must consider that the length of the muscle, shortened or elongated, should not be considered the determining factor of its higher or lower capacity to produce force, but this ability depends on the muscular length within the length-tension relationship curve (19-21).

Although there are some studies reporting an association between PA and joint angle, few studies conducted with this specific objective are reported in the literature. Herbert and Gandevia (9) indirectly sought a relationship between these variables in the brachialis muscle producing isometric torque between $0 \%$ and $100 \%$ of MVC, with the elbow positioned at $90^{\circ}$ and fully extended. The authors report a significant 
increase in PA as the intensity of the contraction increases with the elbow at $90^{\circ}$, but did not identify effect of the joint angle on the PA with the resting muscle, which led them to suggest that the joint angle would influence the PA more clearly only during torque exertion as a consequence of the muscle length-tension relationship. In this sense, it can be considered that the association between joint angle and muscle capacity of torque generation may be an element of interaction in the relationship between the joint angle and the PA.

Chleboun et al. (22) measured the PA of biceps femorallis long head, at different hip and knee angles. The authors verified that changes in the PA were more prominent in variations of hip with the knee maintained at the same angle than in the opposite situation, leading the authors to propose that the joint angle affects the PA of the resting muscle (22). Narici et al. (11) investigated the PA of the medial gastrocnemius at rest, keeping the plantar flexion between $90^{\circ}$ and $150^{\circ}$, and report an increase in the mean PA value for each increment of the ankle angle. However, the authors (11) do not provide report of any statistical significance for the increases found. Mairet et al. (10) measured the PA of vastus lateralis of individuals with the muscle resting, and producing isometric torque of $40 \%$ of MVC, at two different knee angle, $10^{\circ}$ and $100^{\circ}\left(180^{\circ}\right.$ corresponded to the full extension). The PA of resting muscle was significantly lower than that while activated at $40 \%$ of MVC with knee at $10^{\circ}$, whereas at $100^{\circ}$ no difference in PA was found when comparing the measured values at rest with those obtained at $40 \%$ of CVM, conducting the authors (10) to propose the existence effect of knee angle in the PA of vastus lateralis.

Although the results of the studies found in the literature regarding the relationship between PA and joint angle are of great relevance, they report a significant effect of PA on resting muscle, and submitted to some contraction intensities, but with a between-joint-angles differences no lower than $45^{\circ}$. Additionally, although the joint angle may be considered as a variable responsible for altering the PA for a given torque performed by a muscle, the effect of muscle torque combined with the joint angle in the PA has not been investigated. Therefore, this study aims to evaluate the effect of two different knee joint angles on the PA of the vastus lateralis muscle while resting and during four isometric intensities of contraction. In addition, the study investigates the effect of the intensity of contraction on the PA, considering the two joint angles.

\section{Methods}

The sample of this study comprised 8 women and 9 men, all healthy, with a mean (standard deviation) of 26.5 (5.1) years old, body mass of $64.4 \mathrm{~kg}$ (12.3) and height of $1.66 \mathrm{~m}$ (0.09), all self-reported as right-handed. The inclusion criterion adopted were the subject to be between 18 and 35 years old, does not present any neuromuscular disorder, previous surgery or regular knee pain. The experimental procedures were approved by the ethical committee for research with human being of the Clementino Chagas Filho Hospital of the Federal University of Rio de Janeiro, under the clearance number 1.455.075, and all subjects signed the informed consent form, after receiving instructions regarding the procedures that they would be submitted to.

The experimental protocol consisted of isometric tests performed on an isokinetic dynamometer Biodex (System4 PRO). The individual was positioned seated, with the hip maintained at about $90^{\circ}$, and fixed to the equipment with the aid of belts. Then, the height and horizontal position of the equipment chair were adjusted so that the axis of rotation of the dynamometer was aligned as much as possible with the center of rotation of the knee, which was estimated as the midpoint of its joint interline. After positioning the subject, the equipment calibration procedures were performed, which included the measure of leg weight, the angular position of the knee at full extension $\left(180^{\circ}\right)$, full flexion and at $90^{\circ}$. In order to familiarize the subject with the equipment he was instructed to perform knee extensions at low-intensity torque.

Initially, the subjects performed the maximum voluntary contraction (MVC) tests lasting $5 \mathrm{~s}$ each, with the knee at $90^{\circ}$ and $120^{\circ}$ (180o corresponded to full extension). Three attempts with a between interval of 2 min were performed, and the highest torque value obtained from these trials was computed as the reference for the other tests. The order of execution of such tests (at $90^{\circ}$ and $120^{\circ}$ ) was counterbalanced among individuals. Following, the subjects achieved a single repetition of isometric torque at each of the following intensities: $25 \%, 50 \%$ and $75 \%$ of the value of the highest torque obtained during the MVC tests, with the knee at $90^{\circ}$ (total of three tests), and at $120^{\circ}$ (total of three tests). The order of execution of these six tests by the each subject was also counterbalanced, and a 2 min of between-tests rest interval was allowed. In order to guarantee that the subjects would perform these contractions with submaximal intensities, a horizontal 
straight line was presented on the Biodex computer screen, which represented the target value of the torque to be achieved and held for $5 \mathrm{~s}$. Thus, the duration of each submaximal test depended on the time the individual took to reach the target torque, which ranged from $1 \mathrm{~s}$ to $3 \mathrm{~s}$. To perform all tasks, the positioning of the knee angle at $90^{\circ}$ and $120^{\circ}$ was established by the software that controls the dynamometer, in such a way that the subjects' leg was passively driven by the equipment until the angle of the knee reached the selected value.

The PA of the vastus lateralis muscle was measured from all tests. PA was also obtained during rest at both knee angles. For this purpose, a linear ultrasound transducer $(7.5 \mathrm{MHz})$ of ultrasound equipment Aloka (SSD 900) was used and the evaluations were done in B mode. After applying gel to the transducer head, this was maintained during the test over the skin of the individual thigh, perpendicular to the sagittal plane and oriented longitudinally to the thigh axis. The ultrasound image obtained was frozen on the equipment screen so that the PA was taken immediately after the end of each test. By using the software resources of the equipment, the evaluator traced two lines, one in the direction of the fascicles and the other aligned to that of the deep aponeurosis of the muscle (Figure 1). The angle formed between this two lines was defined as the PA $(22,23)$. The value of the PA provided by the equipment software was then recorded. All procedures related to PA acquisition, which included transducer manipulation and PA measuring were performed by only one evaluator.

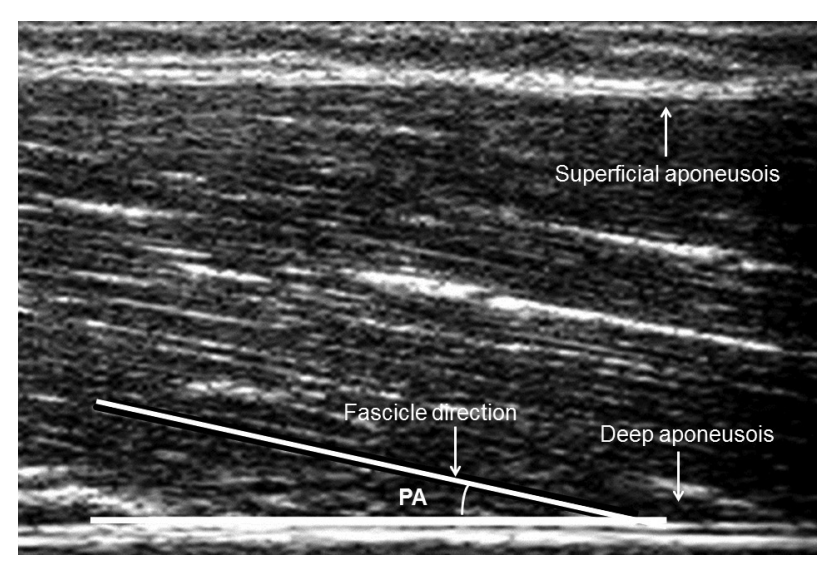

Figure 1 - Illustration of the muscular ultrasonography image, where the directions of the fascicles and of the aponeurosis are shown. The highlighted white lines, which correspond to straight lines that were drawn to measure the PA, arrows and texts, were edited on a photo taken from the screen of the ultrasound equipment.
The Shapiro-Wilk normality test was applied to the PA measured during the different contraction intensities and both knee angles, as well as to the torques produced, and all variables showed to be normality distributed. The highest torque value generated with the knee at $90^{\circ}$ was compared to that at $120^{\circ}$ by means of paired t-test. The effect of the intensity of contraction (resting, 25\%, $50 \%, 75 \%$ and $100 \%$ ) on PA was tested by means of repeated measures ANOVA, and the effect size values (ES) were also calculated. Sphericity was confirmed by the Mauchly's test. When statistical significance was obtained, the post hoc test of Bonferroni was applied. The ES was computed as the Cohen's $d$ for dependent samples, calculated by means of Equation 1 (24). The effect of the knee angle on PA was tested by paired t-test applied to each intensity of contraction. Additionally, the following statistics were determined: the intraclass correlation (ICC), calculated by means of Equation 2 (25), the standard deviation of measurement (SEM), by Equation 3 (25), and the ES. The objective of ES calculation in this study was to serving as a comparison parameter between the effects on PA due to contraction intensity vs. due to the knee angle. The software used for the statistical calculations was SPSS 19 for Windows and the level of significance adopted in all tests was 0.05 .

$$
E S=\frac{\left(\bar{x}_{2}-\bar{x}_{1}\right)}{\sqrt{\left[\frac{S_{2}^{2}\left(n_{2}-1\right)+S_{1}^{2}\left(n_{1}-1\right)}{n_{1}+n_{2}-2}\right] \cdot(1-r)}}
$$

Where $\bar{x}_{2}$ e $\bar{x}_{1}, S_{2}^{2}$ e $S_{1}^{2}$ are the means and respective variances of PA found in two tests from which the ES is to be calculated, $r$ is the Pearson correlation coefficient calculated between the pairs of data of the respective tests, and in the current study, $n_{1}=n_{2}=N$ (number of subjects in the sample).

$$
\begin{aligned}
& I C C=\left(M S_{B}-M S_{W}\right) /\left[M S_{B}+(k-1) M S_{W}\right] \\
& S E M=\sqrt{(1-I C C} \cdot \sqrt{\left(S_{B}^{2}+S_{W}^{2}\right) /(n-1)}
\end{aligned}
$$

Where, all parameters used in the above equations are obtained from the table of one-way repeated measures ANOVA. $M S_{B}$ and $M S_{W}$, are the variance, $S_{B}^{2}$ and $S_{W}^{2}$ the sums of squares of the between and within groups, respectively, $k-1$ is the degree of freedom of treatments, and $n$ is the simple size. 


\section{Results}

The mean value (standard deviation) of the maximum torque generated with the knee at $120^{\circ}$ was $178.4(52.4) \mathrm{Nm}$, a significantly higher value $(\mathrm{p}=0.001)$ than that generated at $90^{\circ}$, which was 153.9 (42.1) Nm, and only two individuals produced slightly less torque at $120^{\circ}$ than at $90^{\circ}$. The mean PA values of the resting muscle at $90^{\circ}$ and $120^{\circ}$ were $11.4^{\circ}\left(3.4^{\circ}\right)$ and $10.8^{\circ}\left(3.5^{\circ}\right)$, respectively, and did not present any statistical significant difference ( $p=0.589, \mathrm{ES}=0.16)$. In addition, there was no significant difference between PAs when comparing the two knee angles (Figure 2) at the intensities 25\% (p = 0.496, ES = $0.02), 50 \%(p=0.744, E S=0.04), 75 \%(p=0.666$, $\mathrm{ES}=0.20)$, and $100 \%$ of MVC ( $p=0.822$, ES $=0.15)$. The ICC showed a significant association (ICC $=0.77$,
SEM $=1.0, p<0.001$ ) between PA measurements at both knee angles during all contractions and for resting muscle (Figure 3 ).

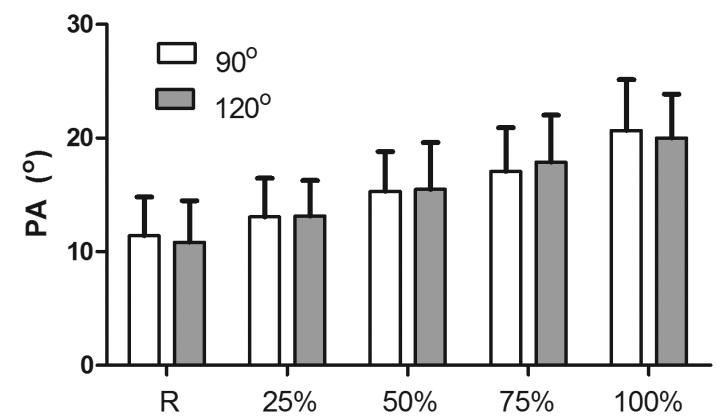

Figure 2 - Mean value ( +1 standard deviation) of the pennation angle $(\mathrm{PA})$ measured with the resting muscle $(\mathrm{R})$ and during the isometric tests at $25 \%, 50 \%, 75 \%$ of the MVC $(100 \%)$ with the knee at $90^{\circ}$ and $120^{\circ}$.
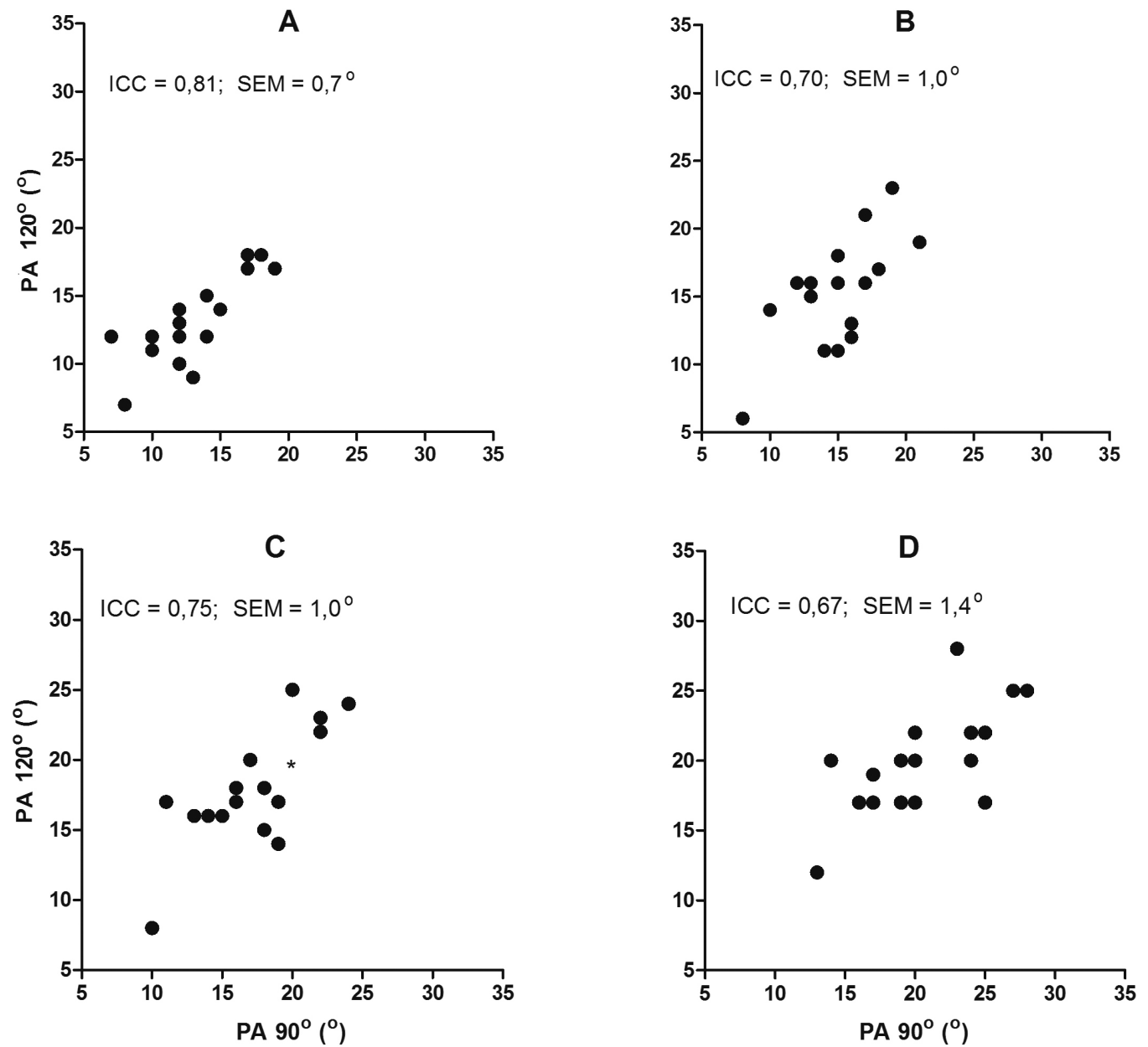

Figure 3 - Scatter plots of the measured PA with the knee at $90^{\circ}$ and $120^{\circ}$ at the intensities of contraction $25 \%$ (A), $50 \%$ (B), $75 \%$ (C) and $100 \%$ (D), together with the intraclass correlation coefficients (ICC) and the standard error of measure (SEM) determined from each pair of variable. 
When testing the effect of intensity of contraction on PA there was a significant difference (Figure 4) between successive intensities exerted with the knee at $90^{\circ}$, rest compared to $25 \%(\mathrm{ES}=1.11$ ), between $25 \%$ and $50 \%$ (ES $=1.61$ ), $50 \%$ compared to $75 \%(E S=1.77)$, and $75 \%$ to that of $100 \%$

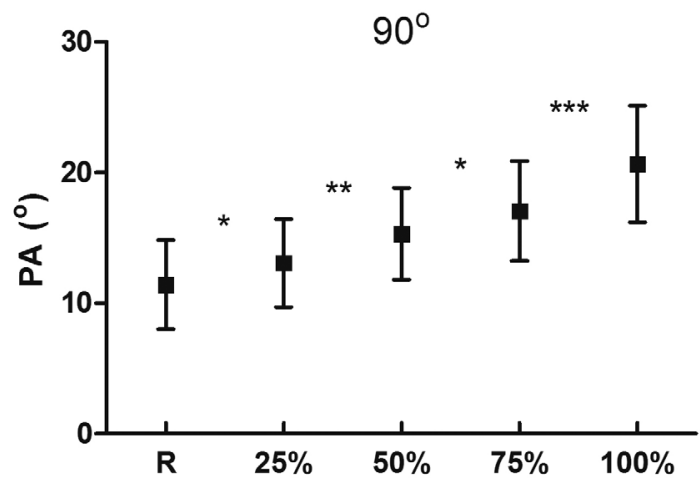

(ES = 3.04). Significant differences between the PA of the contraction intensities were also observed with the knee at $120^{\circ}$ (Figure 4), comparing the rest with $25 \%(E S=1.78), 25 \%$ with $50 \%$, $(E S=1.85)$, $50 \%$ with $75 \%(E S=2.13)$ and $75 \%$ with $100 \%$ $(\mathrm{ES}=2.69)$.

Figure 4 - Mean value ( \pm 1 standard deviation) of the pennation angle $(\mathrm{PA})$ measured with the resting muscle (R) and in the isometric tests at $25 \%, 50 \%, 75 \%$ and $100 \%$ of the MVC with the knee at $90^{\circ}$ and $120^{\circ}$. Significant statistical differences when comparing successive intensities are marked on figure as $* p<0.05$, ** $p<0.01$ and $* * * p<0.001$. The $p$ values were obtained from the post hoc test of Bonferroni.

\section{Discussion}

This research investigated if the PA of VL at rest and during four intensities of isometric contraction is altered by a $30^{\circ}$ variation of knee angle. Additionally, the influence of torque intensity on PA was evaluated. Regarding the torque value generated during the MVC, the results of showed the maximum extensor isometric torque at $120^{\circ}$ of knee flexion to be higher than the obtained at $90^{\circ}$. Kubo et al. (17) found knee extensors peak torque at $110^{\circ}$ in normal subjects during isokinetic exercise. Brughelli et al. (16), comparing the isokinetic peak torque of cyclists and football players, observed values within the range of $110^{\circ}$ and $120^{\circ}$ of knee flexion. Saito and Akima (18), on the other hand, found lower isometric strength of knee extensors at $120^{\circ}$ than $90^{\circ}$. The mean (standard deviation) of the PA with the resting muscle found in the present study was $11.4^{\circ}\left(3.4^{\circ}\right)$ with the knee at $90^{\circ}$ and $10,8^{\circ}\left(3,5^{\circ}\right)$ at $120^{\circ}$, which are similar to that previous reports by Mairet et al. (10), which observed $11.0^{\circ}\left(1.8^{\circ}\right)$ at $80^{\circ}$, an angle close to the $90^{\circ}$ employed in this research, and to the $12,8^{\circ}\left(2,1^{\circ}\right)$ measured with the knee at $90^{\circ}$ found by Brancaccio et al. (26), but below the $15,1^{\circ}\left(3,8^{\circ}\right)$ reported by Chauhan et al. (27). The $1^{\circ}$ value for the SEM of the PA found in the present study for the resting muscle, calculated from the values obtained with the knee at $90^{\circ}$ and $120^{\circ}$, corroborates the affirmation that the measurements obtained here for the PA at rest are within a range comparable to the results presented previously, with individuals sitting with the knee close to $90^{\circ}$ of flexion $(10,26)$.

There are reports in the literature that PA has an instantaneous influence on the strength or torque exerted by the muscle $(9,11,22,27,28)$. Manal et al. (28), who measured PA of plantar flexors, found a successive increase of the PA when increasing the contraction intensity between 0 and $100 \%$ of MVC, with step of $25 \%$. Herbert and Gandevia (9) also reported a significant increase of PA of the brachiallis muscle with the augmentation of the demanded torque between $0 \%$ and $100 \%$ of the MVC. Mairet et al. (10) estimated the PA of the VL indirectly, from the mean length of the muscle fascicles, and reported that a mean value at rest was significantly lower than at $40 \%$ of the MVC with the knee at $170^{\circ}$ of flexion, but no difference was observed with the knee at $80^{\circ}$. These authors (10) justify their findings proposing that the lengthening or shortening the patellar and quadriceps tendons would influence ability of the muscle fascicles to produce force due to the changing of their architecture. However, this argument seems to explain very little this finding, since PA is a 
variable that must be inserted in the modeling of the behavior of the muscle length-tension relationship curve (29), indicating that the PA is part of the cause and not the effect of the muscular capacity of force generation. A difference between the results found in the present study and those of Mairet et al. (10) may be related to the method employed to calculate the PA, since these authors determined PA from the fascicle length and not by means of the method employed in the present study and by others researchers that report results similar values to those found here $(9,10)$.

Considering the results presented in the literature, it was expected effect of the intensity of contraction on the PA of VL. On the other hand, the present research did not expected that while comparing successive intensities of contraction the increase of the PA would show statistically difference at both angles. Chauhan et al. (28) measured the PA of the VL using the same torque intensities investigated in the present study and with the knee at $90^{\circ}$, in order to establish an equation to estimate the PA based on the intensity of EMG of VL. The authors (28) report an increase of PA concomitant with the increase of the exerted torque, but did not test whether the observed differences were statistically significant, probably because such interest was not part of the scope of the study. In the present research, the comparisons between the PAs of the different contraction intensities were performed not only with the $\mathrm{p}$ value statistic, but also with the ES. The purpose of introducing the ES was to serve as a parameter of comparison between the effects on the PA from the intensity of contraction against that caused by the knee angle. The ES values obtained for the effect of intensity (between 1.11 and 3.04) would be classified as ranging between moderate and high (30). As such classification has been proposed to evaluate the effectiveness of physical training (30), the judgment on the concepts of moderate and high should be considered with caution regarding its applicability to the current study.

It has been advocated the existence of effect joint angle on PA, but there are few studies reported in the literature with this specific objective. An important limitation on this subject is the lack of information on the minimal difference between joint angles that can induce a significant alteration in the PA. In fact, published studies have measured PA at some joint angles, but statistical tests comparing the effect of these angles on PA are only presented with betweenjoint angles differences of not less than $45^{\circ}$. Narici et al. (11) investigated a lower angular variation, evaluating the PA of the medial gastrocnemius of six individuals during rest, with plantar flexion between $90^{\circ}$ and $150^{\circ}$, in steps of $5^{\circ}$. Although the authors report an increase of the mean PA value concomitant with increase of the ankle angle, they do not report whether this increase was statistically significant, probably due to the small number of subjects investigated. Thus, it is difficult to evaluate the between joint angles difference that effectively promoted a PA significant alteration in such a research (11). Herbert and Gandevia (9) indirectly sought a relationship between these variables in the brachialis muscle during the production of isometric torque between $0 \%$ and $100 \%$ of MVC, with the elbow at two angles, $90^{\circ}$ of flexion and full extended. The authors (9) found no effect of the joint angle on PA with the resting muscle. The plot of torque vs. PA with the elbow at $90^{\circ}$ showed a significant increase of the PA as the torque increased (9). However, as with the elbow extended this relationship (torque-PA) was not so pronounced, the authors (9) suggested that the joint angle may influence PA when the muscle executes torque as a consequence of the muscular length-tension relationship.

Chleboun et al. (22) measured the PA of the long head of the relaxed biceps femoris, modifying the hip and knee joint angles $\left(0^{\circ}\right.$ - full extension, $45^{\circ}$ and $\left.90^{\circ}\right)$. Changes on PA were more due to changes of hip position with the position of the knee held constant than the contrary. To the authors (22), such results would indicate that the joint angle affects the PA of the resting muscle. Mairet et al. (10) measured the VL of subjects while seated resting and producing isometric torque at $40 \% \mathrm{MVC}$ with the knee at $10^{\circ}\left(0^{\circ}\right.$ is full extension) and $100^{\circ}$. The PA while resting was significantly lower than at $40 \%$ MVC with the knee at $10^{\circ}$, but there was no significant difference between these intensities at $100^{\circ}$, results that led the authors (10) to propose the existence effect of knee angle on PA of vastus lateralis. In the present study such relationship was not observed. The difference between the findings of Mairet et al. (10) and those of the present may be due to the difference of joint amplitude employed during the tests, $30^{\circ}$ in the present study vs. $80^{\circ}(10)$. In this context, the statistical values obtained while associating PA measured at the knee angles investigated here $\left(90^{\circ}\right.$ and $\left.120^{\circ}\right)$, during all contraction and rest intensities, showed to be within the limits reported in the literature for ICC (0.51 to 1.00) and SEM (from $0.1^{\circ}$ to $1.2^{\circ}$ ), from reliability studies of 
the PA measurement $(31,32)$. These results indicate that the PA found at both knee angles had very similar values, and the differences found could be considered as inherent to random errors and therefore not associated with the knee joint position. In addition, the ES values calculated for the two angles were very small at all intensities of contraction and rest, especially when compared to the effect of contraction intensity. Thus, it seems that $30^{\circ}$ is not a knee between-angles difference enough to promote change on PA of VL muscle, at least when testing $90^{\circ}$ against $120^{\circ}$. Future studies should identify the minimum difference of joint angle that can induce significant effect on PA of VL at different contraction intensities.

\section{Conclusion}

The results of this study showed a successive and significant increase of PA as a result of intensity of the contraction, corroborating reports in the literature that propose an association between these two variables. The calculated ES values due to intensity of contraction would be situated between weak and moderate, however, such classification is proposed to test the effectiveness of physical training, and therefore should be applied with caution to the results presented here. Even though it is proposed that the PA is modified by joint angle, when comparing the knee at $90^{\circ}$ with $120^{\circ}$ no effect of joint angle on AP of the vastus lateralis muscle at rest and during the executed torques was found. It is recommended that studies should be carried out to identify the minimum between-joint angles difference that promotes alteration in the AP of the VL at different contraction intensities.

\section{References}

1. Narici M. Human skeletal muscle architecture studied in vivo by non-invasive imaging techniques: functional significance and applications. J Electromyogr Kinesiol. 1999;9(2):97-103.

2. Maganaris CN. A predictive model of moment angle characteristics in human skeletal muscle: Application and validation in muscles across the ankle joint. J Theor Biol. 2004;230(1):89-98.
3. Kawakami Y, Abe T, Kuno SY, Fukunaga T. Traininginduced changes in muscle architecture and specific tension. Eur J Appl Physiol Occup Physiol. 1995;72(1-2):37-43.

4. De Boer MD, Seynnes OR, DI Prampero PE, Pisot R, Mekjavić IB, Biolo G, et al. Effect of 5 weeks horizontal bed rest on human muscle thickness and architecture of weight bearing and non-weight bearing muscles. Eur J Appl Physiol. 2008;104(2):401-7.

5. Miyatani M, Kanehisa H, Ito M, Kawakami Y, Fukunaga T. The accuracy of volume estimates using ultrasound muscle thickness measurements in different muscle groups. Eur J Appl Physiol. 2004;91(2-3):264-72.

6. Blazevich A, Cannavan D, Coleman D, Horne S. Influence of concentric and eccentric resistance training on architectural adaptation in human quadriceps muscles. J Appl Physiol (1985). 2007;103(5):1565-75.

7. Aagaard P, Andersen J, Dyhre-Poulsen P, Leffers AM, Wagner A, Magnusson SP, et al. A mechanism for increased contractile strength of human pennate muscle in response to strength training: changes in muscle architecture. J Physiol. 2001;534(Pt. 2):613-23.

8. Reeves ND, Maganaris CN, Narici MV. Ultrasonographic assessment of human skeletal muscle size. Eur J Appl Physiol. 2004;91(1):116-8.

9. Herbert RD, Gandevia SC. Changes in pennation with joint angle and muscle torque: in vivo measurements in human brachialis muscle. J Physiol. 1995;484(Pt 2):523-32.

10. Mairet S, Maïsetti O, Portero P. Homogeneity and reproducibility of in vivo fascicle length and pennation determined by ultrasonography in human vastus lateralis muscle. Sci Sports. 2006;21(5):268-72.

11. Narici MV, Binzoni T, Hiltbrand E, Fasel J, Terrier F, Cerretelli P. In vivo human gastrocnemius architecture with changing joint angle at rest and during graded isometric contraction. J Physiol. 1996;496(Pt 1):287-97. 
12. Hansen EA, Lee HD, Barrett K, Herzog W. The shape of the force-elbow angle relationship for maximal voluntary contractions and submaximal electrically induced contractions in human elbow flexors. J Biomech. 2003;36(11):1713-8.

13. Koo TK, Mak AF, Hung LK. In vivo determination of subject-specific musculotendon parameters: applications to the prime elbow flexors in normal and hemi paretic subjects. Clin Biomech (Bristol, Avon). 2002;17(5):390-9.

14. Leedham JS, Dowling JJ. Force-length, torque-angle and EMG-joint angle relationships of the human in vivo biceps brachial. Eur J Appl Physiol Occup Physiol. 1995;70(5):421-6.

15. Linnamo V, Strojnik V, Komi PV. Maximal force during eccentric and isometric actions at different elbow angles. Eur J Appl Physiol. 2006;96(6):672-8.

16. Brughelli M, Cronin J, Mendiguchia J, Kinsella D, Nosaka K. Contralateral leg deficits in kinetic and kinematic variables during running in Australian rules football players with previous hamstring injuries. J Strength Cond Res. 2010;24(9):2539-44.

17. Kubo K, Tsunoda N, Kanehisa H, Fukunaga, T. Activation of agonist and antagonist muscles at different joint angles during maximal isometric efforts. Eur J Appl Physiol. 2004;91(2-3):349-52.

18. Saito A, Akima H. Knee joint angle affects EMGforce relationship in the vastus intermedius muscle. J Electromyogr Kinesiol. 2013;23(6):1406-12.

19. Brockett CL, Morgan DL, Proske U. Human hamstring muscles adapt to eccentric exercise by changing optimum length. Med Sci Sports Exerc. 2001;33(5):783-90.

20. Koh TJ. Do adaptations in serial sarcomere number occur with strength training? Hum Mov Sci. 1995;14(1):61-77.

21. Savelberg HHCM, Meijer K. Contribution of mono and biarticular muscles to extending knee joint moments in runners and cyclists. J Appl Physiol (1985). 2003;94(6):241-8.

22. Chleboun GS, France AR, Crill MT, Braddock HK, Howell JN. In vivo measurement of fascicle length and pennation angle of the human biceps femoris muscle. Cells Tissues Organs. 2001;169(4):401-9.
23. Fukunaga T, Ichinose $Y$, Ito M, Kawakami Y, Fukashiro S. Determination of fascicle length and pennation in a contracting human muscle in vivo. J Appl Physiol (1985). 1997;82(1):354-8.

24. Cohen J. Statistical Power Analysis for the Behavioral Sciences. 2nd ed. Hillsdale, NJ: L. Erlbaum Associates; 1988. p. xxi-567.

25. Weir JP. Quantifying test-retest reliability using the intraclass correlation coefficient and the SEM. J Strength Cond Res. 2005;19(1):231-40.

26. Brancaccio P, Limongelli FM, D'Aponte A, Narici M, Maffulli N. Changes in skeletal muscle architecture following a cycloergometer test to exhaustion in athletes. J Sci Med Sport. 2008;11(6):538-41.

27. Chauhan B, Hamzeh MA, Cuesta-Vargas AI. Prediction of muscular architecture of the rectus femoris and vastus lateralis from EMG during isometric contractions in soccer players. Springerplus. 2013;2:548.

28. Manal K, Roberts DP, Buchanan TS. Can pennation angles be predicted from EMGs for the primary ankle plantar and dorsiflexors during isometric contractions? J Biomech. 2008;41(11):2492-7.

29. Chang YW, Su FC, Wu HW, An KN. Optimum length of muscle contraction. Clinic Biomech (Bristol, Avon). 1999;14(8):537-42.

30. Rhea MR. Determining the magnitude of treatment effects in strength training research through the use of the effect size. J Strength Cond Res. 2004;18(4):918-20.

31. Kwah LK, Pinto RZ, Diong J, Herbert RD. Reliability and validity of ultrasound measurements of muscle fascicle length and pennation in humans: a systematic review. J Appl Physiol (1985). 2013;114(6):761-9.

32. Ward SR, Eng CM, Smallwood LH, Lieber RL. Are Current Measurements of Lower Extremity Muscle Architecture Accurate? Clin Orthop Relat Res. 2009;467(4):1074-82.

Received in $04 / 25 / 2016$

Recebido em 25/04/2016

Approved in 04/10/2017

Aprovado em 10/04/2017 